\title{
Forthcoming Events
}

The Association for Research in Nervous and Mental Disease will hold its annual meeting on 5 and 6 December, 1980 at the Grand Hyatt Hotel in New York City. The meeting will be devoted to the 'Genetics of Neurological and Psychiatric Disorders'. Information: Secretary-Treasurer of the "ARNMD, Bernard Cohen, Mount Sinai School of Medicine, 1 Gustave Levy Place, NY 10029, USA.

The Brtibh Paycho-Analytieal Society is holding a daycourse of lectures and discussion entitled 'Basic Psycho-
Analytical Concepts' on 22 November, 1980 at the Institute of Psycho-Analysis. The Course, recognized under Section 63, has special relevance to the MRCPsych Examination. Information: Honorary Secretary, Public Lectures Committee, Institute of Psycho-Analysis, 63 New Cavendish Street, London WIM 7RD.

A Workshop in Peychodrama led by Marcia Karp, graduate of the Moreno Academy, will be held at Warneford Hospital from 28 February to 2 March 1981. Information: Dr S. Bloch, Warneford Hospital, Oxford OX3 7JX.

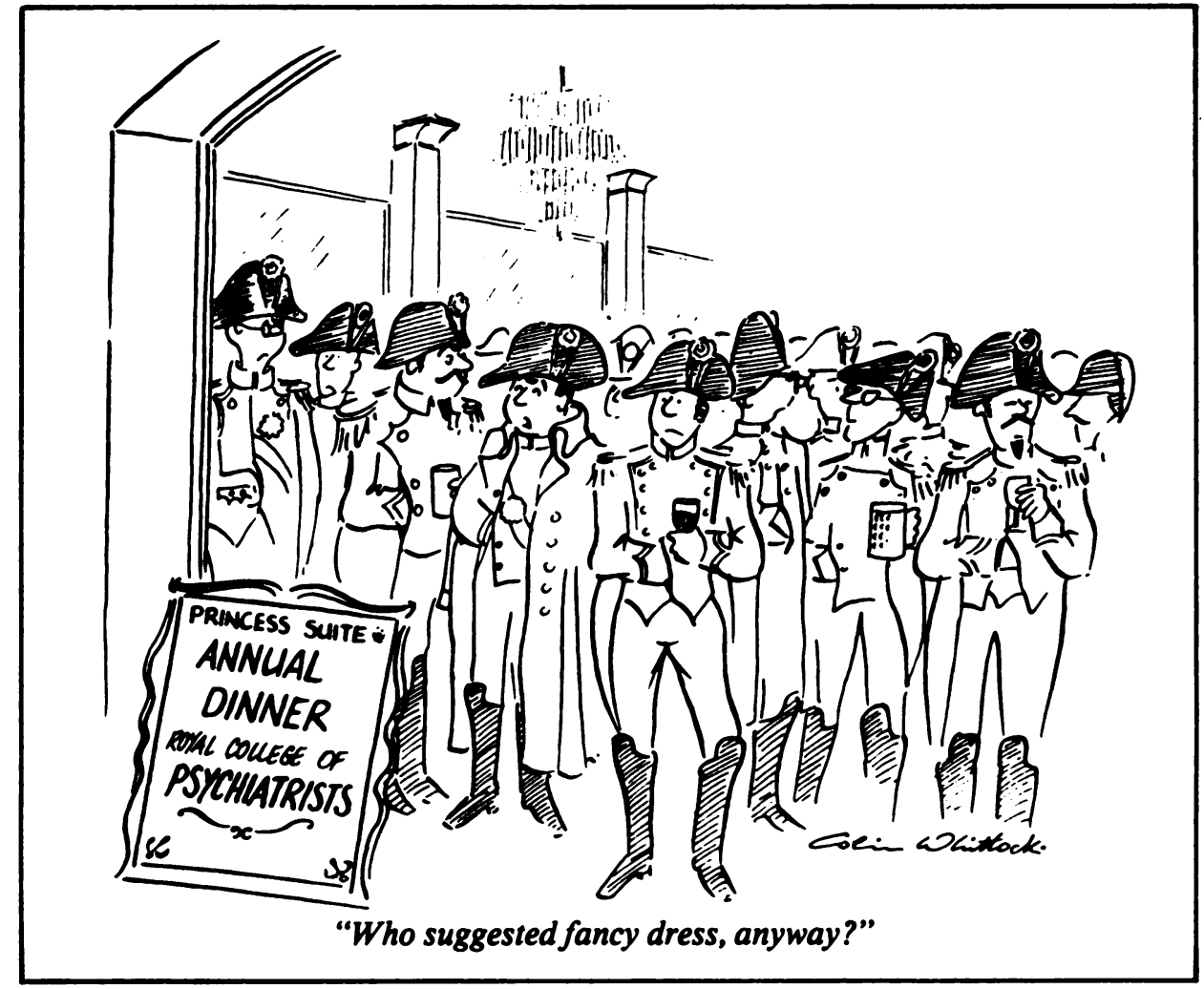

Reproduced by permission of Punch.

Printed in Great Britain by Headley Brothers Ltd The Invicta Press Ashford Kent and London 